\title{
Movement behaviour of the small benthic Rhine sculpin Cottus rhenanus (Freyhof, Kottelat \& Nolte, 2005) as revealed by radio-telemetry and pit-tagging
}

\author{
Michaël Ovidio • Aurélie Detaille • \\ Charlotte Bontinck • \\ Jean-Claude Philippart
}

Received: 17 March 2009/Revised: 24 August 2009/Accepted: 7 September 2009/Published online: 19 October 2009

(C) Springer Science+Business Media B.V. 2009

\begin{abstract}
From February 2006 to June 2007, we followed the movement patterns of the Rhine sculpin (Cottus rhenanus) by combining short-term radiotelemetry ( $n=10$ radio-tagged sculpin with a miniature 0.5-g transmitter) and long-term individual (PIT-tag) mark-recapture ( $n=452$ PIT-tagged sculpin during six removal electric fishing operations) studies in a small tributary of the River Meuse, Belgium. During a 25- to 27-day period, the radio-tracked sculpin displayed various mobility patterns, showing frequent movement from one day to another and longitudinal home ranges from 7 to $46 \mathrm{~m}$, with cumulative distances up to $149 \mathrm{~m}$. During the mark-recapture study, most (99\%) recaptured PIT-tagged individuals moved from their original 5-m long site, subsequently using longitudinal home ranges between 5 and $435 \mathrm{~m}$ (mean, $50 \mathrm{~m}$; median, $20 \mathrm{~m}$ ). The most common movement behaviour was alternation between upstream and downstream movements $(62 \%)$, followed by directional upstream (26\%) and directional downstream (11\%) movement. Using the latest available techniques, this study builds on the current knowledge on the Cottus genus and closes gaps
\end{abstract}

Handling editor: J. A. Cambray

M. Ovidio $(\varangle) \cdot$ A. Detaille $\cdot$ C. Bontinck ·

J.-C. Philippart

University of Liège, Biology of Behaviour Unit,

Laboratory of Fish Demography and Hydroecology,

10 Chemin de la Justice, 4500 Tihange, Belgium

e-mail: m.ovidio@ulg.ac.be in the comprehension of sculpin movement and home range at a scale that had not been investigated to date.

Keywords Mobility · Home range ·

Small benthic species - PIT-tag - Telemetry ·

Cottus

\section{Introduction}

Despite the technological advances made in tagging devices (reduction of size and weight) for the study of fish movements (Beeman et al., 2007), we know very little about some aspects of the behavioural patterns (home range, mobility, habitat use) of non-game fish, especially small-bodied benthic species (Petty \& Grossman, 2004). Yet, this information is valuable from both basic and applied scientific perspectives. For example, it would be difficult to predict the effects of an environmental disturbance without knowledge of the home ranges of the species in the affected area. In addition, quantification of the home ranges of assemblage members is desirable in studies of assemblage organisation (in Hill \& Grossman, 1987).

Small bottom-dwelling freshwater fish of the Cottus genus (family: Cottidae) are frequently threatened species in major parts of their distribution areas as a result of anthropogenic habitat destruction (Utzinger et al., 1998). Traditional mark-recapture studies have been predominantly employed to study the mobility of these species. Even if short-distance 
movement behaviour $(<50 \mathrm{~m})$ has sometimes been observed (Downhower et al., 1990), most studies predominately demonstrated a high level of residency and limited movements and/or home ranges (Smyly, 1957; Andreasson, 1971; Goto, 1986; Hill \& Grossman, 1987; Lelek, 1987; Petty \& Grossman, 2004).

Using miniature luminous diodes, Natsumeda (2007) demonstrated the ability of the fluvial sculpin (Cottus pollux) to display different short-term nocturnal movements. By individual tagging of fish with the passive integrated transponder (PIT-tag), Knaepkens et al. $(2004,2005)$ suggested that the freshwater sculpin (Cottus gobio) might sometimes consist of both stationary and mobile individuals that can cover 10- to 260-m distances over a 7-month period. More recently, using a portable antenna, Breeder et al. (2009) showed that in Cottus bairdii $16 \%$ of PITtagged individuals moved more than $100 \mathrm{~m}$ over 1 year. More specific studies would nevertheless be particularly useful to better understand the sculpin's use of space at a longer time scale, but they require more repeated successive locations of tagged individuals over time (Juanes et al., 2000). This is a frequent situation in small-body fish species whose behavioural ecology is often much less well-known than the patterns of larger fish species that are easier to tag and follow (Lucas \& Baras, 2001).

Our study was designed to carry out such original observations on short- and long-term movement patterns and the spatial distribution of the recently described Rhine sculpin Cottus rhenanus (formerly C. gobio, Freyhof et al., 2005) using two complementary methodologies. First, an intensive campaign to position individuals equipped with a miniature radio transmitter during two different 1-month periods (winter and spring), and, second, multiple recaptures of a great number of PIT-tagged individuals during a period extending over more than 1 year. Our main objectives were to test the existence of movement behaviour in the Rhine sculpin as well as their use of space and time at the short and long time scales.

\section{Materials and methods}

Study area

The Falogne brook is 6.9-km-long tributary of the Fonds d'Oxhe stream, which directly flows through the River Meuse in Amay (Belgium). The stream morphology is natural with respect to bank structure, substrate and flow regime. The mean slope is $28.8 \%$, and the fish population is predominately composed of brown trout (Salmo trutta) and Rhine sculpin. The river is heavily shaded by a fairly dense vegetation (Alnus glutinosa, Fraxinus excelsior, Picea abies). In normal flow conditions, the mean width of the stream in the study area is $3.7 \mathrm{~m}$ and the mean depth is $15 \mathrm{~cm}$. Based on a Wentworth scale (Wentworth, 1922), the substratum is predominately composed of pebbles, cobbles and boulders.

The mean water temperature at the Falogne brook is $10.3^{\circ} \mathrm{C}$, ranging from 0.1 to $19.8^{\circ} \mathrm{C}$ (recorded from February 2006 to December 2007). The flow was not recorded but a limnimetric scale was placed in the stream before starting the telemetry study (in February 2007) and flow was then manually recorded during the tracking sessions. During large floods (Fig. 1), sporadic manual measurements indicated that flow can reach $0.6 \mathrm{~m}^{3} \mathrm{~s}^{-1}$ in the Falogne brook.

Radio-telemetry study

On 20 February and 22 May 2007, electric fishing was carried out in the Falogne brook to capture and select large individual sculpins for the telemetry study. Selected individuals (Table 1) were anaesthetised in a 2-phenoxy-ethanol solution $\left(0.2 \mathrm{ml} \mathrm{l}^{-1}\right)$ and were then laid with their ventral side uppermost on a wetted tissue soaked with anaesthetic. An incision was made laterally, between the opercula and the pelvic girdle. A radio transmitter (model F1526; ATS Inc., Isanti, MN, USA; $49 \mathrm{MHz}$, trailing whip antenna $160 \mathrm{~mm}$ long, $0.5 \mathrm{~g}$ in air, $5 \times 13 \mathrm{~mm}, 21$-day battery life) was inserted through the incision. For all ten tagged fish, the tag mass/body mass ratio varied from 1.41 to $2.55 \%$ and antenna length/body length ranged from 1.26 to 1.49 (Table 1). The incision was closed with two independent resorbable sutures (Vycril 5/0, 3/8c). As the skin of the sculpin is extremely delicate, the transmitter antenna exited the body of the fish by a small slit in the scar and did not lead out through a separate hole as is usually done (Jepsen et al., 2002). Individual surgery took between 3 and $5 \mathrm{~min}$. Tagged fish were allowed a 30-min recovery in a tank before being released at their exact capture site. This short recovery period was chosen to reduce the potential effects from postoperative care and to replace the fish 
Fig. 1 Variations in the mean daily water temperature $\left({ }^{\circ} \mathrm{C}\right)$ in the Falogne stream from February 2006 to April 2007 and indication of the dates on which electric removal fishing was conducted for the markrecapture study. Black circles indicate major floods events during the study period

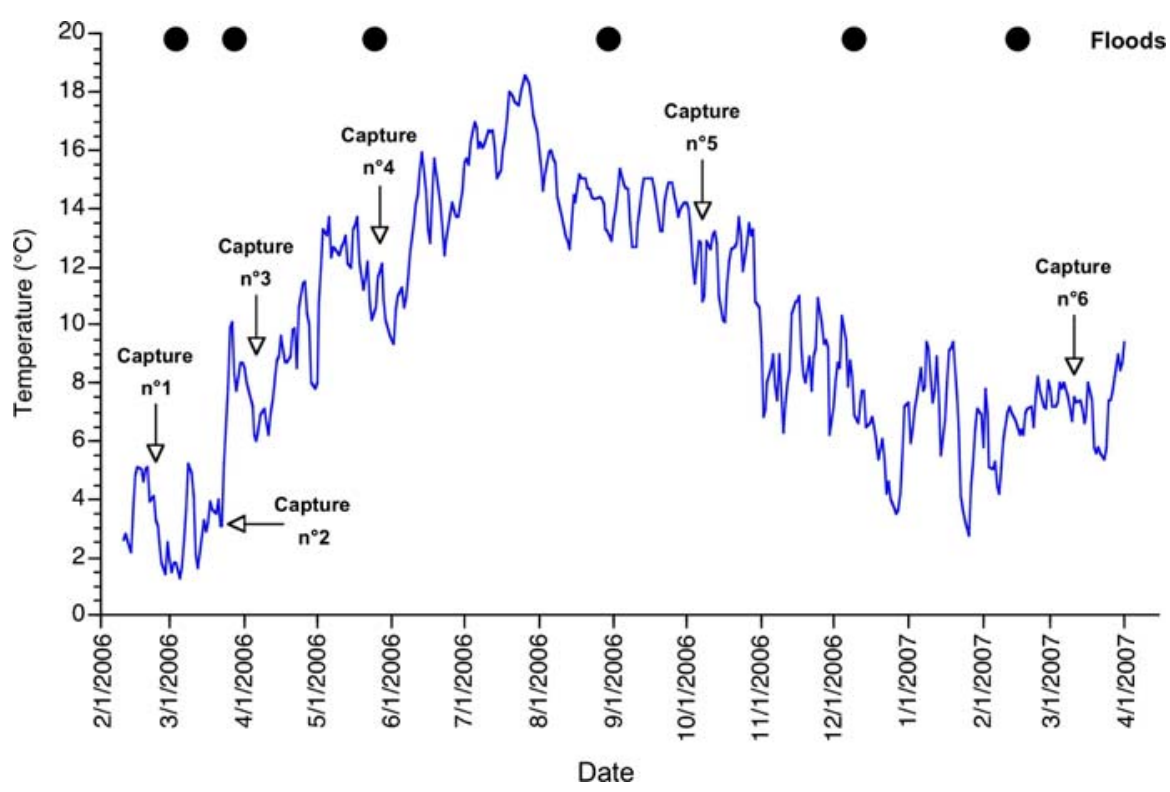

Table 1 Characteristics of the radio-tracked sculpin, extent of their individual longitudinal home ranges and cumulated distances covered during the entire tracking period

\begin{tabular}{|c|c|c|c|c|c|c|c|}
\hline Fish no & $\begin{array}{l}\text { Total length } \\
(\mathrm{mm})\end{array}$ & $\begin{array}{l}\text { Weight } \\
(\mathrm{g})\end{array}$ & $\begin{array}{l}\text { Fish-antenna } \\
\text { length ratio }(\%)\end{array}$ & $\begin{array}{l}\text { Tagging } \\
\text { date }\end{array}$ & $\begin{array}{l}\text { Tracking } \\
\text { duration (day) }\end{array}$ & $\begin{array}{l}\text { Longitudinal } \\
\text { home range }(\mathrm{m})\end{array}$ & $\begin{array}{l}\text { Cumulative } \\
\text { displacement } \\
\text { distances (m) }\end{array}$ \\
\hline 1 & 122 & 35.4 & 1.31 & $20 / 02 / 2007$ & 25 & 10 & 57 \\
\hline 2 & 122 & 29.7 & 1.31 & $20 / 02 / 2007$ & 25 & 7 & 48 \\
\hline 3 & 126 & 28.2 & 1.27 & $20 / 02 / 2007$ & 25 & 11 & 63 \\
\hline 4 & 115 & 24.9 & 1.39 & $20 / 02 / 2007$ & 25 & 15 & 78 \\
\hline 5 & 127 & 24.2 & 1.26 & $20 / 02 / 2007$ & 25 & 22 & 66 \\
\hline 6 & 119 & 20.3 & 1.34 & $22 / 05 / 2007$ & 27 & 46 & 126 \\
\hline 7 & 116 & 20.3 & 1.38 & $22 / 05 / 2007$ & 27 & 46 & 149 \\
\hline 8 & 115 & 19.6 & 1.39 & $22 / 05 / 2007$ & 27 & 10 & 22 \\
\hline 9 & 107 & 20.7 & 1.49 & $22 / 05 / 2007$ & 27 & 16 & 43 \\
\hline 10 & 117 & 21.3 & 1.37 & $22 / 05 / 2007$ & 27 & 11 & 40 \\
\hline
\end{tabular}

in their environment as soon as possible. The $2 \times$ $n=5$ fish were located during two 25- to 30-day tracking sessions that started on 20 February 2007 and on 22 May 2007. Tagged sculpins were located at least every day alternating between 9 and $12 \mathrm{~h}$ or 14 and $17 \mathrm{~h}$. Fish were not tracked for the first $24-\mathrm{h}$ period after their release to avoid biased observations that may reflect a traumatic state just after capture and tagging (Ovidio et al., 2007). Locations were made using a mobile FieldMaster radio receiver and a loop antenna (ATS Inc.) making sure to approach the site with the greatest possible precautions to avoid disrupting the fish. The accuracy of the localisation was tested before the tracking session with hidden transmitters, showing that the maximum loss of precision reached only $1 \mathrm{~m}$ in $10 \%$ of the cases. Most of the test locations (90\%) were more precise than $0.5 \mathrm{~m}$. This high level of precision results mainly from the narrowness of the stream and the placement of the antenna directly at the top of the transmitter in combination with classical triangulation methods.

Mark-recapture study

A 300-m river stretch of the Falogne stream, free of any obvious obstacles, was selected as our standard study 
site (this site is located $150 \mathrm{~m}$ downstream of the telemetry study site). The site was subdivided into $n=605-\mathrm{m}$ long sectors using colour landmarks. From 21 February 2006 to 21 March 2007 (Fig. 1), $n=6$ removal electric fishing operations were conducted using exactly the same methodology: (i) two successive passages, one electrode (Deka 3000 portable electrofishing unit, pulse DC $600 \mathrm{~V}$ ), one hand net and two persons to collect the fish and (ii) fish captured in each 5-m stretch were isolated in separate tanks. During the first fishing session (21/02/2006), each fish was individually weighed, measured and sexed if sexually mature. Sculpin heavier than $3.2 \mathrm{~g}$ were equipped with an individual coded PIT-tag (Trovan, ID $100,2.12 \times 11.5 \mathrm{~mm}$; operation frequency, $128 \mathrm{kHz}$ ) according to the methodology proposed by Knaepkens et al. (2007). PIT-tagged sculpin were double marked with colour elastomer (NMT international) in order to estimate the retention rate of the transponder. During the other fishing sessions, all captured sculpins were measured, weighed, sexed and scanned to detect the potential presence of a PIT-tag and the associated location of the fish. Non-tagged individuals heavier than $3.2 \mathrm{~g}$ were systematically PIT-tagged. The day after each capture session, additional electric fishing was conducted $150 \mathrm{~m}$ up- and downstream of the study area to detect the presence of individuals that had left the 300-m study site. An insurmountable weir prevented the sculpin from moving more than $150 \mathrm{~m}$ upstream of the reference study site. Individual tagging allowed us to calculate different variables:

- The displacement distance between two successive recaptures with a 5-m precision, while considering the upstream and downstream directions. An individual recaptured in the same river section was considered immobile. A movement from sector $0-5$ to sector $10-15$ was considered +10 . As electric fishing did not occur at a single time interval, this data was standardised as displacement distance per week in the analyses (Rogers \& White, 2007).

- The cumulative displacement distance was calculated on the same basis, without considering movement direction. As electric fishing did not occur at a single time interval, this data was standardised as cumulative displacement distance per week in the analyses (Rogers \& White, 2007).
- The longitudinal home range corresponded to the distances separating the most downstream and the most upstream locations of an individual during the entire study period (Ovidio et al., 1998). Depending on the individual considered, it was calculated on the basis of two to five recaptures.

At each fishing session, recaptured individuals were classified into three different categories:

Sedentary: remained in the same area since the previous capture. Intermediate: moved to the adjacent section $(-5$ or +5$)$ since the previous capture. Mobile: moved more than one section away since the previous capture.

\section{Results}

Telemetry study

Movement patterns were variable and complex (Fig. 2a, b) during both the winter and spring tracking sessions. The movement pattern of fish no. 8 must be viewed with caution because its transmitter was recovered near the last site occupied continually at the end of the tracking session. The fish may have died prior to the end of the study. During the 25 days of tracking in winter (Fig. 2a), the tracked sculpin occupied a longitudinal home range spanning 7 to $22 \mathrm{~m}$ and the total distance covered by the sculpin ranged from 48 to $78 \mathrm{~m}$ in 25 days (Table 1). During the 27 days of tracking in spring (Fig. 2b), the tracked sculpin occupied a longitudinal home range spanning from 11 to $46 \mathrm{~m}$ and the total distance covered by the sculpin ranged from 22 to $149 \mathrm{~m}$ in 28 days (Table 1 ).

The cumulative distances travelled between consecutive days by the radio-tracked sculpin were greater in spring than in winter (Mann-Whitney $U$ test: $U=1684, \mathrm{~N} 1=\mathrm{N} 2, P<0.001)$. Nevertheless, no difference was observed between movement direction in spring and summer (Sign test, $P>0.05$ ).

Mark-recapture study

A total number of $n=452$ sculpin were PIT-tagged during the study period and $n=205$ individuals were recaptured at least once (186 at the study site and 19 outside the study site). The efficiency of the electric fishing varied from 55 to $87 \%$ (De Lury, 1947). 

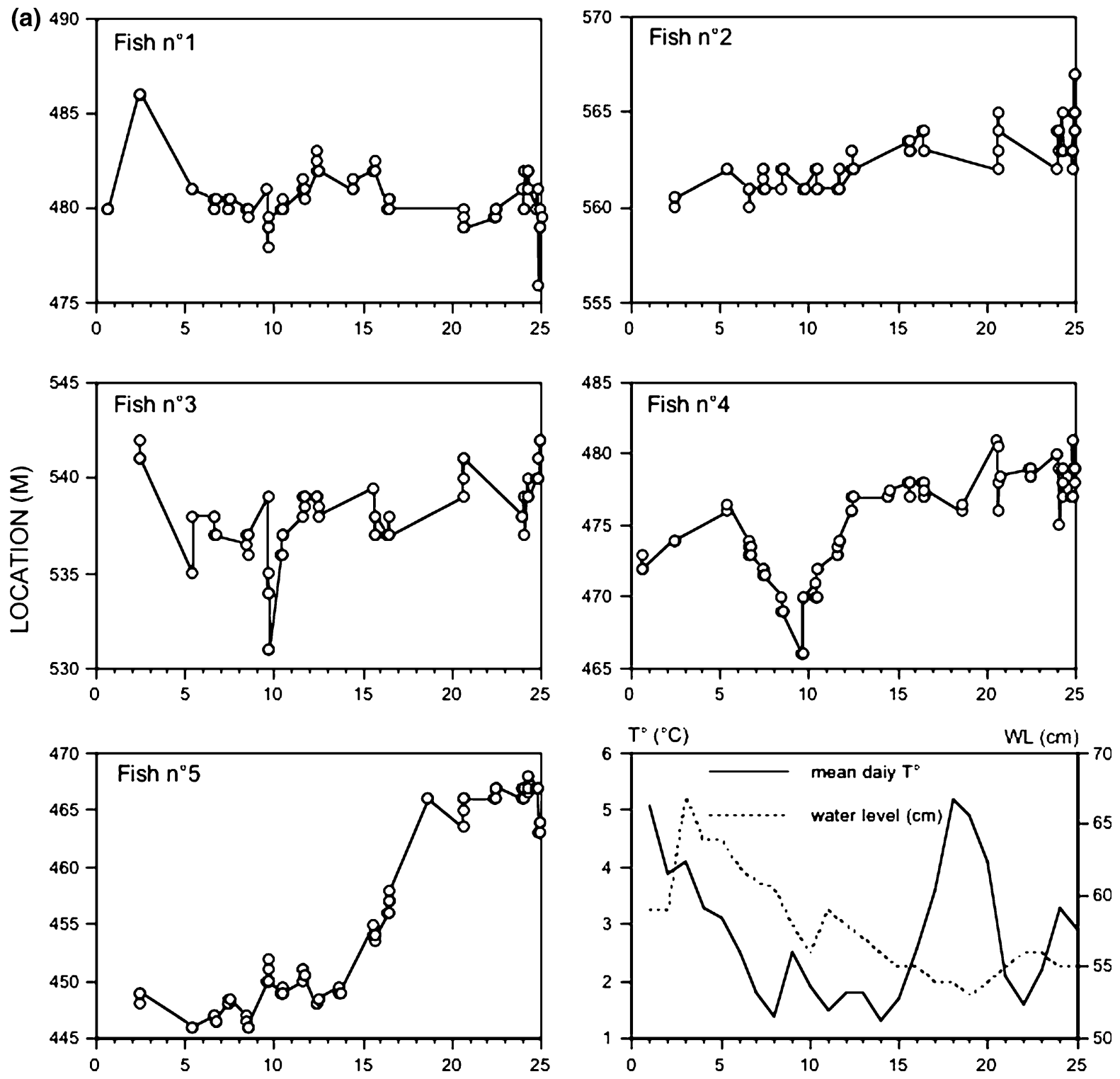

DAYS SINCE TAGGING

Fig. 2 a Mobility patterns of the five individual sculpin radiotracked from 20 February to 17 March 2007 and variations in the water level and the mean daily water temperature during the same period. b Mobility patterns of the five individual

Based on the double-marking method, it appeared that $1 \%$ of the PIT-tagged sculpin lost their tags during the study period. Of the 205 recaptured individuals, $1.5 \%(n=3)$ were recaptured four times, $7.3 \%(n=15)$ were recaptured three times, $20.5 \%$ $(n=42)$ were recaptured twice and $70.7 \%(n=145)$ were recaptured once. The longitudinal home ranges sculpin radio-tracked from 22 May to 18 June 2007 and variations in the water level and the mean daily water temperature during the same period

of these $n=205$ sculpin varied from 5 to $435 \mathrm{~m}$, with a mean of $49.8 \mathrm{~m} \pm 5.01 \mathrm{SE}$ and a median of $20 \mathrm{~m}$. The movement distances between successive recaptures varied from -395 to $250 \mathrm{~m}$ (Fig. 3).

The mean cumulative distances travelled per week were greatest during the capture sessions ranging from March to April 2006 (6.8 m) and were the least 

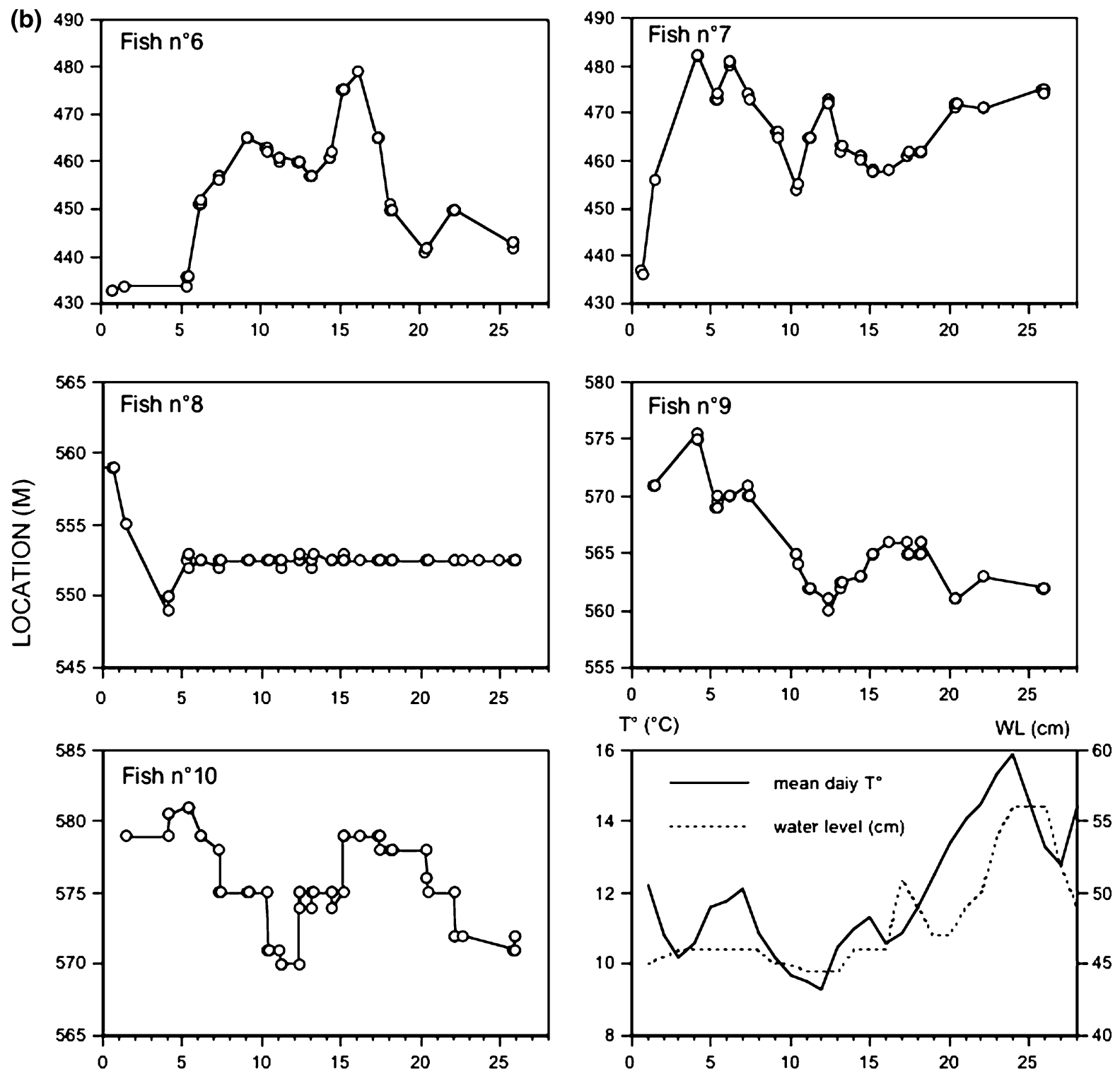

DAYS SINCE TAGGING

Fig. 2 continued

during the session ranging from February to March (Table 2). A Friedman test indicated a difference in the distances covered between the different recapture dates $\left(\chi^{2}, 25.3\right.$; DF, $\left.4 ; P<0.0001\right)$.

The proportion of sedentary fish decreased from the beginning to the end of the study, reaching a minimum in March 2007 (4.3\% of sedentary fish). The proportion of mobile individuals generally increased from the beginning to the end of the study, reaching up to
76.2\%. Recapture may, however, include fish tagged in an earlier mark-recapture session.

No significant differences were observed between the mean distances covered per week by males and females at each recapture date or when considering the sum of the captures during the entire study period (McNemar test $P$ always $>0.05$ ). When grouping all of the recaptured sculpin in three body size categories (60-80 mm; 81-100 mm; >100 mm), no significant 
Fig. 3 Frequency histogram of movement distances of PIT-tagged sculpin from February 2006 to April 2007 including captures within and outside the standard study site

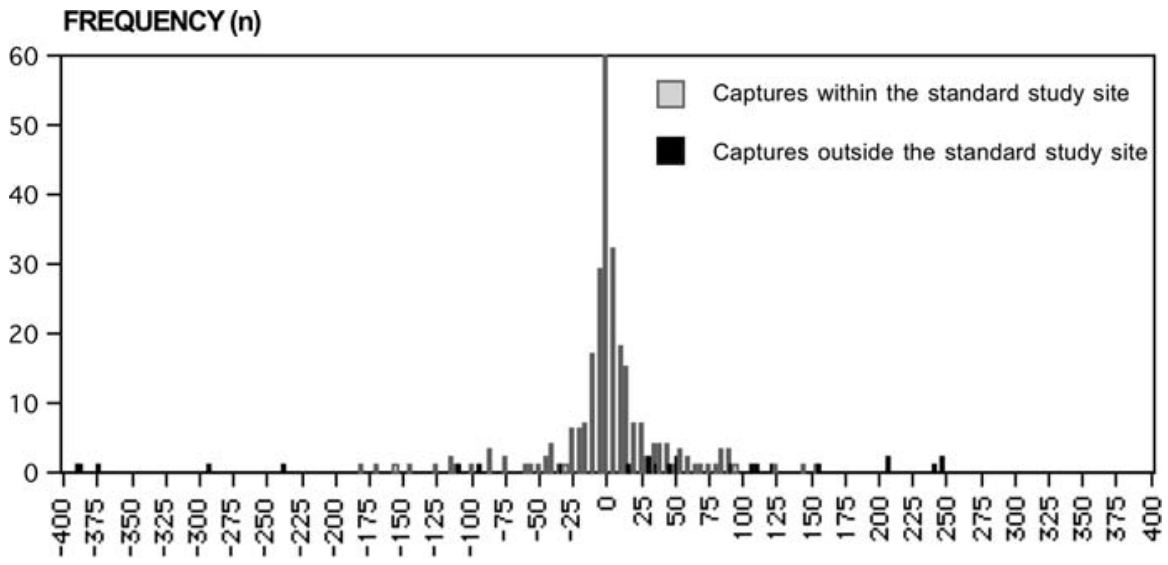

MOVEMENT DISTANCES (m)

Table 2 Mobility variables associated with the mark-recapture study (PIT-tagged individuals) from February 2006 to March 2007

\begin{tabular}{lllllrr}
\hline Periods & $\begin{array}{l}\text { Recaptured } \\
(n)\end{array}$ & $\begin{array}{l}\text { Mean } \\
\text { temperature } \\
\text { during the } \\
\text { period }\left(^{\circ}\right)\end{array}$ & $\begin{array}{l}\text { Mean } \\
\text { cumulative } \\
\text { distance per } \\
\text { week (m } \pm \text { SE) }\end{array}$ & $\begin{array}{l}\text { Sedentary } \\
\text { fish \% }\end{array}$ & $\begin{array}{l}\text { Intermediate } \\
\text { fish } \%\end{array}$ & $\begin{array}{l}\text { Mobile } \\
\text { fish } \%\end{array}$ \\
\hline 21 February 2006 to 22 March 2006 & 52 & 2.3 & $0.7 \pm 0.12$ & 53.9 & 36.5 & 9.6 \\
22 March 2006 to 11 April 2006 & 58 & 7.1 & $6.8 \pm 1.3$ & 24.1 & 15.5 & 21.2 \\
11 April 2006 to 24 May 2006 & 66 & 10.9 & $4.2 \pm 0.7$ & 19.7 & 50.4 \\
24 May 2006 to 3 October 2006 & 42 & 13.9 & $1.7 \pm 0.3$ & 9.5 & 23.8 & 66.7 \\
3 October 2006 to 21 March 2007 & 46 & 9.0 & $1.4 \pm 0.26$ & 4.3 & 19.5 & 76.2 \\
\hline
\end{tabular}

Sedentary fish: remained in the same area since the previous capture. Intermediate fish: moved in the adjacent section $(-5$ or +5$)$ since the previous capture. Mobile fish: moved more than one section away since the previous capture

differences were observed between the three groups (Friedman test; DF: $2 ; \chi^{2}$ value: 1,$861 ; P=0.394$ ).

Of the $n=57$ sculpin that were recaptured at least twice, it appears that individuals who alternate upstream and downstream movements were the most frequent in the population (62\%) followed by individuals moving only in the upstream direction (26\%) and only in the downstream direction (11\%). Nonmovement was the least frequent behavioural pattern observed (1\%).

\section{Discussion}

The tagging of small-bodied fish species requires the use of adapted marking and innocuous devices that can provide a high retention rate. As was suggested by Bruyndoncx et al. (2002) and Knaepkens et al. (2007), our results confirm that using a passive integrated transponder (PIT-tag) to tag sculpin meets these criteria if all the suggested precautions are applied. In our study, the estimated retention reaches $99 \%$ (PIT-tagged sculpin were double marked with colour elastomer) and the recaptured individuals healed perfectly.

Micro-telemetry had not yet been applied to smallbodied benthic fish of the Cottus genus. Recent studies have suggested that implanting small fish such as juvenile salmonids with transmitters weighing from 2 to $12 \%$ of body weight does not affect the swimming performance of fish (Brown et al., 1999; Robertson et al., 2003; Lacroix et al., 2004; Økland et al., 2004, Enders et al., 2007; Ovidio et al., 2007). However, it has been suggested that the presence of a trailing whip antenna may sometimes cause changes in social status (Connors et al., 2002), predator avoidance (Adams 
et al., 1998) and a significant decrease in swimming performance if its length reaches $300 \mathrm{~mm}$ (Murchie et al., 2004). In this study, in order to minimise the potential effect of the tag on sculpin behaviour, the transmitters weighed a maximum of $2.55 \%$ of the body mass and the trailing antenna was reduced to $160 \mathrm{~mm}$. Recapturing radio-tagged sculpin 10 days after the tracking period (40 days after tagging) showed that the healing process (including the antenna exit) was well underway, not completely finished but showing no infection or necrosis. However, one of the ten tagged sculpin had lost its transmitter or died during or just after the tracking session.

The combination of two different methodologies (i) intensive tracking of a small number of radio-tagged individuals over a short time scale with a $10-$ to $15-\mathrm{cm}$ precision and (ii) PIT-tagging with multiple recaptures over a long period of time with a precision of $5 \mathrm{~m}$ allowed us to better understand the movement patterns and spatial distribution of individual Rhine sculpin over short and long time periods. Our results suggest that our subpopulation of Rhine sculpin routinely exploit habitats extending over tens to hundreds of metres, whereas traditional thinking would suggest that they extend over several metres to tens of metres (Petty \& Grossman, 2004). The investigated population developed different types of movement patterns like most large-bodied stream-resident fish species (Lucas \& Baras, 2001), albeit at a smaller spatial scale.

The population studied was mostly composed of individuals moving bidirectionally. Another part of the population comprises individuals moving unidirectionally upstream or moving unidirectionally downstream. These individuals may play a major role in colonisation and hybridisation processes (Nolte et al., 2006), since they are potentially able to move several kilometres per year in the same direction. This means that, like most stream-resident fish species, they might also be disturbed by habitat fragmentation (Utzinger et al., 1998; Fischer \& Kummer, 2000; Ovidio \& Philippart, 2002). Surprisingly, our study suggested that non-movement (i.e. an individual that stayed consistently in the same 5-m river section during the annual cycle) was the least frequent behavioural pattern observed in the population investigated. The difference between our results and most previous studies may be partially explained by the methodologies used. Our results suggest that shortterm mark-recapture experiments might support the description of a high level of residence within a population between two successive recaptures. When the recaptures of the same individual are multiplied over a longer time period, it becomes clear that most of them move during the annual cycle (Gowan et al., 1994). The intensive tracking of radio-tagged individuals over a 1month period confirms and amplifies the perception of movement in the sculpin population because it clearly suggests that most of the tracked individuals moved frequently from one day to another and sometimes showed their ability to modify their behavioural patterns over time. The longitudinal home ranges recorded during the 1-year mark-recapture study are vast in comparison with previous studies, with a maximum distance covered of $435 \mathrm{~m}$, with a mean of $49.8 \mathrm{~m}$ and a median of $20.0 \mathrm{~m}$. Interestingly, longitudinal home ranges recorded by telemetry during a 1-month period on a day-by-day basis (max, $46 \mathrm{~m}$; mean, $19.4 \mathrm{~m}$; median, $13.0 \mathrm{~m}$ ) are also higher than those observed during longer periods in previous mark-recapture studies on Cottus species (Bailey, 1952; McCleave, 1964; Downhower et al., 1990; Petty \& Grossman, 2004).

Our records corroborate those of Knaepkens et al. (2004, 2005), who also used PIT-tags and demonstrated that $C$. gobio sometimes produced upstream movements reaching $100 \mathrm{~m}$ and downstream movements as long as $260 \mathrm{~m}$ in a small stream of Northern Belgium. However, based on the taxonomic revision of Freyhof et al. (2005), studies in Europe might concern different Cottus species, which complicates the comparisons, even in different river basins in the same country (i.e. France, Belgium). Furthermore, it is important to emphasise that our results may not be generalised to the entire population since the sculpin used in this study weighed at least $3.2 \mathrm{~g}$ to be PITtagged and we tracked large adults only ( $>19.6 \mathrm{~g})$.

In Northern Belgium, Knaepkens et al. (2004) demonstrated that $C$. gobio mobility was higher from May to June than from January to February. In our study site, the movements recorded during the spring-summer period were also longer than those recorded in fall and winter, with a maximum observed in March-April, which may be linked to the reproduction period as females were mainly mature during this period.

Acknowledgements This research is part of the "Obstruction to Fish Migration" project, which receives financial support from the Ministry of Natural Resources and Environment (D.G.R.N.E.) of Wallonia, Belgium, represented by F. Lambot and P. Orban. J.C. Philippart is a Research Associate from the 
Belgian "Fonds National de la Recherche Scientifique". The authors wish to thank Gilles Rimbaud, Yvan Neus, L. Jonlet, M. Darimont and A.M. Massin for field support. We also thank Alexander Kobler, Niels Jepsen and an anonymous referee for constructive comments and Linda Northrup (English Solutions) for the English-language editing of the manuscript.

\section{References}

Adams, N. S., D. W. Rondorf, S. D. Evans, J. E. Kelly \& R. W. Perry, 1998. Effects of surgically and gastrically implanted radio transmitters on swimming performance and predator avoidance of juvenile chinnok salmon (Oncorhynchus tshawytscha). Canadian Journal of Fisheries and Aquatic Sciences 55: 781-787.

Andreasson, S., 1971. Feeding habits of a sculpin (Cottus gobio L. Pisces) population. Report of the Institute of Freshwater Research Drottningholm 51: 5-30.

Bailey, J. E., 1952. Life history and ecology of the sculpin Cottus bairdi punctulatus in southwest Montana. Copeia 1952: 243-255.

Beeman, J. W., S. Juhnke, L. Dingmon, M. van den Tillaart \& T. Thomas, 2007. Effects of antenna length and material on output power and detection of miniature radio transmitters. Hydrobiologia 582: 221-229.

Breeder, M. J., C. R. Ruetz, K. J. Thompson \& L. Kohler, 2009. Movements of mottled sculpins (Cottus bairdii) in a Michigan stream: how restricted are they? Canadian Journal of Fisheries and Aquatic Sciences 66: 31-41.

Brown, R. S., S. J. Cooke, W. G. Anderson \& R. S. McKinley, 1999. Evidence to challenge the " $2 \%$ " rule for biotelemetry. North American Journal of Fisheries Management 19: 867-871.

Bruyndoncx, L., G. Knaepkens, W. Meeus, L. Bervoets \& M. Eens, 2002. The evaluation of passive integrated transponder (PIT) tags and visible implant elastomer (VIE) marks as new marking techniques for the bullhead. Journal of Fish Biology 60: 260-262.

Connors, K. B., D. Scruton, J. A. Brown \& R. S. McKinley, 2002. The effects of surgically-implanted dummy transmitters on the behaviour of wild Atlantic salmon smolts. Hydrobiologia 483: 231-237.

De Lury, D. B., 1947. On the estimation of biological population. Biometrics 3: 145-147.

Downhower, J. F., P. Lejeune, P. Gaudin \& L. Brown, 1990. Movements of the chabot (Cottus gobio) in a small stream. Polskie Archiwum Hydrobiologii 37: 119-126.

Enders, E. C., K. D. Clarke, C. J. Pennell, L. M. N. Ollerhead \& D. A. Scruton, 2007. Comparison between PIT and radio telemetry to evaluate winter habitat use and activity patterns of juvenile Atlantic salmon and brown trout. Hydrobiologia 582: 231-242.

Fischer, S. \& H. Kummer, 2000. Effects of residual flow and habitat fragmentation on distribution and movement of bullhead (Cottus gobio L.) in an alpine stream. Hydrobiologia 422(423): 305-317.

Freyhof, J., M. Kottelat \& A. Nolte, 2005. Taxonomic diversity of European Cottus with description of eight new species
(Teleostei: Cottidae). Ichthyological Exploration of Freshwater 16: 107-172.

Goto, A., 1986. Movement and population size of the river sculpin Corms hangiongensis in the Daitobetsu Rixer of southern Hokkaido. Japanese Journal of Ichthyology 32: 421-430.

Gowan, C., M. K. Young, K. D. Fausch \& S. C. Riley, 1994. Restricted movement in resident stream salmonids: a paradigm lost? Canadian Journal of Fisheries and Aquatic Sciences 51: 2626-2637.

Hill, J. \& G. G. Grossman, 1987. Home range estimates for three North American stream fishes. Copeia 372: 376-380.

Jepsen, N., A. Koed, E. B. Thorstad \& E. Baras, 2002. Surgical implantation of telemetry transmitters in fish: how much have we learned? Hydrobiologia 483: 239-248.

Juanes, F., B. H. Letcher \& G. Gries, 2000. Ecology of stream fish: insights gained from an individual-based approach to juvenile Atlantic salmon. Ecology of Freshwater Fish 9: $65-73$.

Knaepkens, G., L. Bruyndoncx \& M. Eens, 2004. Assessment of residency and movement of the bullhead (Cottus gobio) in two Flemish rivers. Ecology of Freshwater Fish 13: 317-322.

Knaepkens, G., K. Baekelandt \& M. Eens, 2005. Assessment of the movement behaviour of the bullhead (Cottus gobio), an endangered European freshwater fish. Animal Biology 55: 219-226.

Knaepkens, G., E. Maerten, C. Tudorache, G. De Boeck \& M. Eens, 2007. Evaluation of passive integrated transponder tags for marking the bullhead (Cottus gobio), a small benthic freshwater fish: effects on survival, growth and swimming capacity. Ecology of Freshwater Fish 16: 404-409.

Lacroix, G. L., D. Knox \& P. McCurdy, 2004. Effects of implanted dummy acoustic transmitters on juvenile Atlantic salmon. Transactions of the American Fisheries Society 133: 211-220.

Lelek, A., 1987. Freshwater Fishes of Europe. Vol. 9: Threatened Fishes of Europe. AULA-Verlag, Wiesbaden: 343 pp.

Lucas, M. \& E. Baras, 2001. Migration of Freshwater Fish. Blackwell Science Ltd., Oxford: 392 pp.

McCleave, J. D., 1964. Movement and population of the mottled sculpin (Cottus bairdi Girard) in a small Montana stream. Copeia 1964: 506-513.

Murchie, K. J., S. J. Cooke \& J. F. Schreer, 2004. Effects of radio-transmitter antenna length on swimming performance of juvenile rainbow trout. Ecology of Freshwater Fish 13: 312-316.

Natsumeda, T., 2007. Estimates of nocturnal home-range size of the adult Japanese fluvial sculpin, Cottus pollux (Pisces: Cottidae) in relation to bottom topography and sampling intervals. Journal of Ethology 25: 87-93.

Nolte, A. W., J. Freyhof \& D. Tautz, 2006. When invaders meet locally adapted types: rapid moulding of hybrid zones between sculpins (Cottus, Pisces) in the Rhine system. Molecular Ecology 15: 1983-1993.

Økland, F., E. B. Thorstad \& T. F. Næsje, 2004. Is Atlantic salmon production limited by number of territories? Journal of Fish Biology 65: 1047-1055.

Ovidio, M. \& J. C. Philippart, 2002. The impact of small physical obstacles on upstream movement of six species of fish. Hydrobiologia 483: 55-69. 
Ovidio, M., E. Baras, D. Goffaux, C. Birtles \& J. C. Phillipart, 1998. Environmental unpredictability rules the autumn migrations of trout (Salmo trutta) in the Belgian Ardennes. Hydrobiologia 372: 262-273.

Ovidio, M., E. C. Enders, E. J. Hallot, M. L. Roy, F. Petit, J. C. Philippart \& A. G. Roy, 2007. Mobility and home-range use of Atlantic salmon parr over short time scales. Aquatic Living Resources 20: 95-101.

Petty, T. J. \& G. D. Grossman, 2004. Restricted movements by mottled sculpin (Pisces: Cottidae) in a southern Appalachian stream. Freshwater Biology 49: 631-645.

Robertson, M. J., D. A. Scruton \& J. A. Brown, 2003. Effects of surgically implanted transmitters on swimming performance, food consumption and growth of wild Atlantic salmon parr. Journal of Fish Biology 65: 1070-1079.
Rogers, K. B., \& G. C. White, 2007. Analysis of movement and habitat use from telemetry data. In Guy, C. S. \& M. L. Brown (eds) Analysis and Interpretation Of Freshwater Fisheries Data. American Fisheries Society, Bethesda: 625-676.

Smyly, W. J. P., 1957. The life-history of the bullhead or Miller's thumb (Cottus gobio L.). Proceedings of the Zoological Society of London 128: 431-453.

Utzinger, J., C. Roth \& A. Peter, 1998. Effects of environmental parameters on the distribution of bullhead Cottus gobio with particular consideration of the effects of obstructions. Journal of Applied Ecology 35: 882-892.

Wentworth, C. K., 1922. A scale of grade and class terms for clastic sediments. Journal of Geology 30: 377-392. 